\title{
PERFORMANCE ANALYSIS AND CONTROL OF A SWITCHED RELUCTANCE GENERATOR
}

\author{
A. F. Ahmed, F. M. El-Kholy, A. S. Abd El-Ghafaar, and A. M. Osheiba \\ Electrical Engineering Department, Faculty of Engineering, \\ Minoufiya University, Shebin El-Kom, Egypt
}

\begin{abstract}
In this paper, a successful design for a 3-phase 6/4 switched reluctance generator (SRG) has been developed, analyzed and tested. The performance characteristics of such a generator type are fully studied using a nonlinear mathematical model. A control technique by which the output power of the SRG can be successfully controlled to follow the maximum output power of a wind turbine drive application has been proposed. Moreover, stabilization of the output voltage of the SRG under varying load conditions is also presented. Meanwhile, the real-time operation was implemented in a digital signal processor (DSP) environment. Digital simulation studies have been carried out for the proposed analysis and the results are compared to those of a practical one. A good agreement between simulation and experimental results has been observed which supports the validity of the proposed analysis.

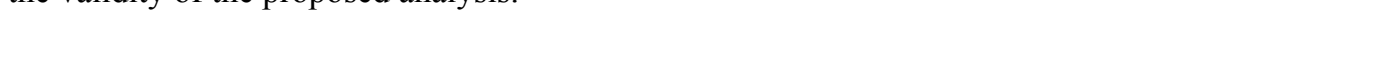

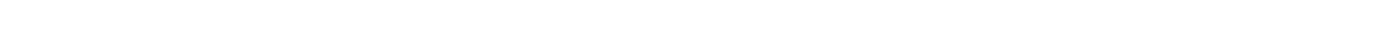

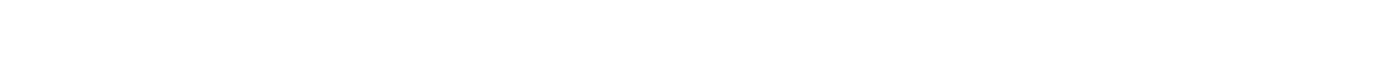

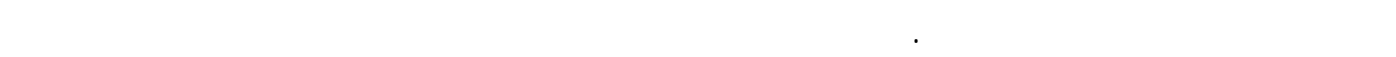

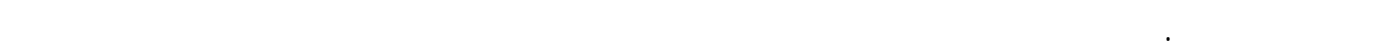

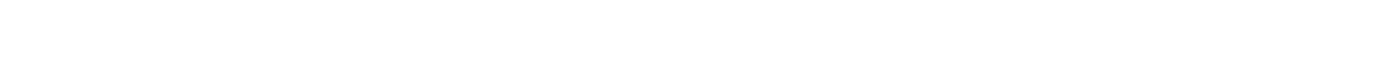

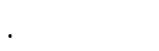

Keywords: Switched reluctance generator, Digital signal processor (DSP), and Power electronics

\section{INTRODUCTION}

The switched reluctance generator has recently been received an increasing amount of interest for a lot of applications. The switched reluctance machines are considered as serious candidates for starter/alternator systems in several electric cars [1]. A switched reluctance variable speed generator system could also have a good prospect for the application of a wind power generation [2]. A stand alone wind generator acting as an output power filter was described in reference [3]. Furthermore, the switched reluctance generator can be used as an auxiliary power unit in high power hybrid vehicle application [4]. Its compatibility with the previous applications is due to its extreme robustness, high efficiency of energy conversion, ability to work over a wide range of speeds, high energy density and control simplicity. The absence of windings or permanent magnets on the rotor helps to keep the majority of losses within the stator, making the SRG relatively easy to cool. The linear and nonlinear mathematical models of the switched reluctance generator in generation mode were established [5]. The performance analysis and control of such a generator have received little attention from the researchers until to date [6]. The aim of this paper is to develop an accurate mathematical model that verifies the experimental results of the SRG behavior in different modes of operation. The output power of the SRG is controlled to track the maximum output power of a wind turbine drive applications. Moreover, the generator output voltage is stabilized under load variations.

\section{SYSTEM DESCRIPTION}

A 6/4 SRG was built and tested in the laboratory. The stator was made by modifying the stator of a conventional 3-phase induction motor. The 36 teeth on the inner stator periphery are divided into six groups. Two teeth of each group were removed regularly to obtain a salient poles stator. The rotor was made of solid steel with dimensions to fit the inner diameter and length of the stator employed [7].

The switched reluctance generator has a 6-pole on the stator and a 4-pole on the rotor as shown in Fig. (1). There is a concentrated coil on each pole. The two coils on the diametrically opposite stator poles could be connected to make up one phase winding, the dimensions of the proposed SRG are listed in Appendix (1). As shown in Fig. (2), the phase winding of the SRG is excited from two main switches and stored energy is delivered to the load by 
two flywheel diodes. The phase windings are excited by turning the two main switches on, to connect the winding to the power supply. The electrical and mechanical energies which are provided by the exterior circuit are converted into magnetic field energy. Once both switches are turned off the generated power will be delivered to the load.

The SRG is coupled to a DC shunt motor which is used as a prime mover. A shaft encoder is fixed on one side of the SRG shaft. A digital signal processor (DSP)-based control board, Dspace 1104, is used to decide the rotor position and then the conduction period for each phase. Using this DSP control board, a closed loop controller is also implemented.

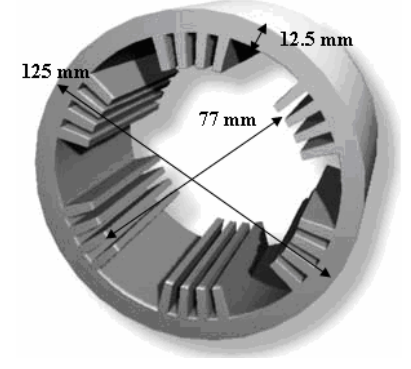

Fig.1 Stator and rotor of a 3-phase

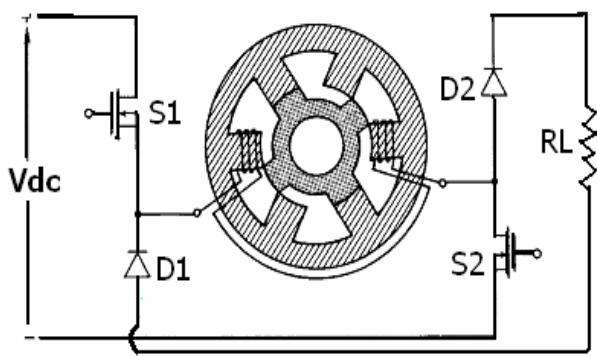

Fig.2 One phase of the SRG source. 6/4 SRG. (All dimensions in $\mathrm{mm}$ )

\section{ENERGY CONVERSION PROCESS}

The change of magnetic field energy for one stroke when the primary switch is turned on is shown in Fig (3). The figure shows the variation of flux linkages with current trajectory during one stroke of SRG operation. The amount of energy involves changes in both of stored energy W1 and mechanical energy W2 due to rotor motion. The excitation energy $\mathrm{W} 1$ is provided by the voltage supply, while the mechanical energy involved in energy conversion process W2 is represented by the enclosed area of flux linkage against current trajectory. Such a trajectory is called the energy loop. The summation of $\mathrm{W} 1$ and $\mathrm{W} 2$ is delivered back to the supply and/or the load depending on the topology of the drive circuit. To achieve successful generation, energy loop trajectory must be in clockwise direction. This situation is possible only when $\theta_{\text {on }}$ is at or near the aligned position. Therefore, SRG can operate continuously as a generator if the bulk of the conduction period occurs during the negative $\mathrm{dL}_{\mathrm{n}} / \mathrm{d} \theta[8]$. This process is repeated for each stroke. For a switched reluctance generator with " $\mathrm{m}$ " phases and $\mathrm{N}_{\mathrm{r}}$ rotor poles generates $\mathrm{mN}_{\mathrm{r}}$ strokes per revolution. To employ such a generator as a stand alone generator, the drive circuit should have the capability of providing excitation power to the machine windings in proper periods and transferring the generated power to the load. This is possible by separating the excitation circuit from the output circuit. When a switch is turned-on, the voltage supply provides the required excitation to the phase windings. This period is known as the excitation period. When the switch is turned-off, the phase current flows through the load resistance until it vanishes. This period is known as the generation period. The load current is the summation of the different phase currents contributions. The energy delivered to the load includes the energy stored in the phase inductance during excitation as well as the energy converted from the mechanical source. There is no energy fed back to the supply. Therefore, it is always desirable to reduce the excitation requirements. The area of the loop represents the output energy may be increased by increasing the maximum inductance and decreasing by decreasing minimum inductance, which may be achieved by a good design.

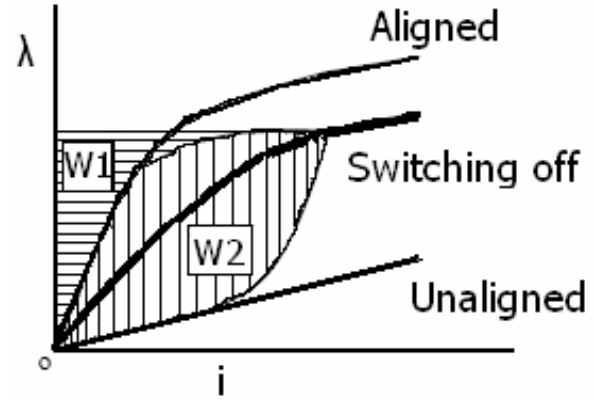

Fig.3. Energy Conversion Loop During One Stroke.

\section{MATHEMATICAL MODEL OF A SRG}

The excitation and generation modes of a SRG are presented in this section.

\subsection{Excitation Mode}

The phase voltage equation for the switched reluctance generator may be written as:

$$
\mathrm{V}=\mathrm{Ri}(\mathrm{t})+\frac{\mathrm{d} \lambda(\mathrm{t})}{\mathrm{dt}}
$$

Where $\mathrm{V}$ is the phase voltage, $\mathrm{R}$ is the phase resistance, $i$ is the phase current, and $\lambda$ is the flux linkage.

Since the inductance $\mathrm{L}$ is a complex function of position and current then the flux linkage may be written as follows; 
A.F. Ahmed, F. El-Kholy, A.S. Abd El-Ghafaar, and A. Osheiba, "Performance Analysis and Control of a SRG"

$$
\lambda(t)=L[i(t), \theta(t)] . i(t)
$$

Consequently, the phase voltage can be re-written as

$$
\mathrm{V}=\mathrm{R} \mathrm{i}(\mathrm{t})+\frac{\mathrm{d}[\mathrm{L}(\mathrm{i}, \theta) \cdot \mathrm{i}]}{\mathrm{dt}}
$$

The rotational mechanical speed is given by;

$$
\omega_{\mathrm{m}}=\frac{\mathrm{d} \theta}{\mathrm{dt}}
$$

Where $\theta$ is the mechanical angle of the rotor position.

\subsection{Generation Mode}

During the generation mode, the phase winding is connected to the load, hence the voltage equation can be written as;

$$
0=\frac{\mathrm{d} \lambda(\theta, \mathrm{i})}{\mathrm{dt}}+\mathrm{R} \mathrm{i}_{\mathrm{ph}}-\mathrm{R}_{\mathrm{L}} \mathrm{i}_{\mathrm{L}}
$$

Where the load current is excited by the current generated by one phase $i_{\text {ph }}$ and other current contributions of other phases $i_{n}$.

$$
\mathrm{i}_{\mathrm{L}}=\mathrm{i}_{\mathrm{ph}}+\mathrm{i}_{\mathrm{n}}
$$

A matlab/simulink program was implemented based the previous model in different modes of operation with a look-up table used to model the nonlinear relation of Fig. (4).

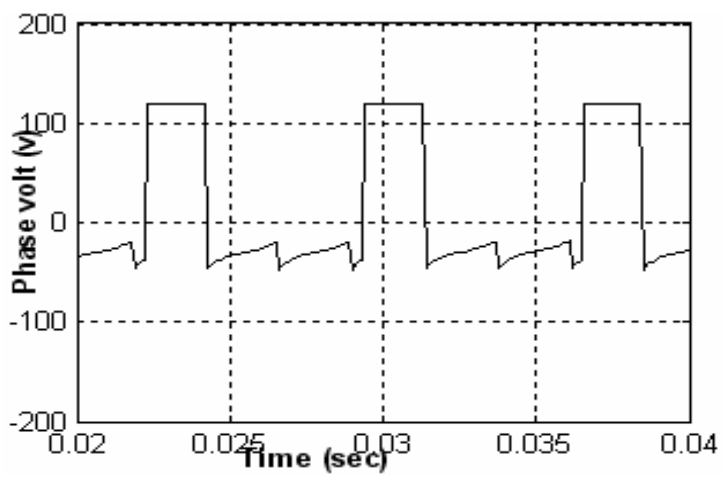

(a)

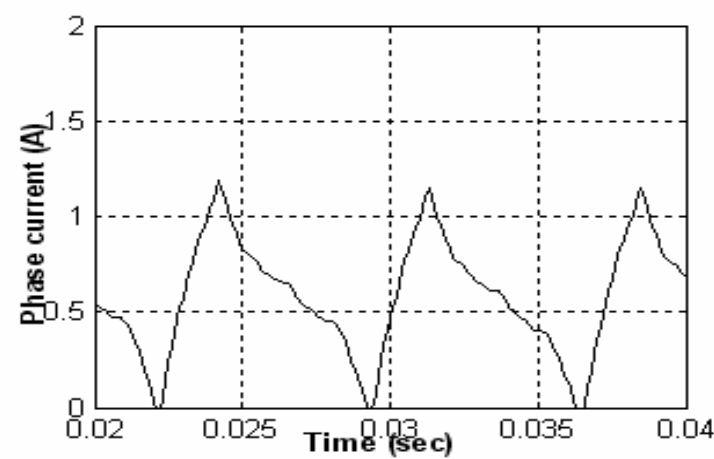

(c)

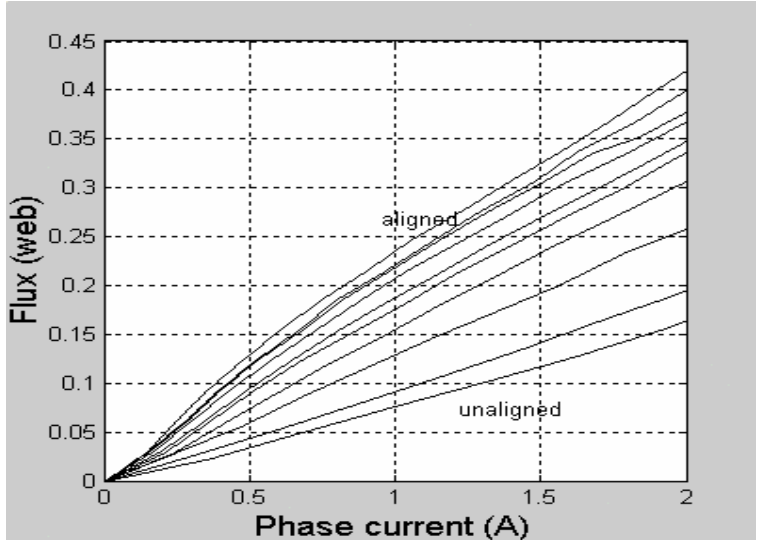

Fig. (4) Variation of flux linkage with current of the $6 / 4 \mathrm{SRG}$ with regular spacing of $5^{\circ}$.

\section{SIMULATION AND EXPERIMENTAL RESULTS}

To study the steady-state and dynamic performance of the proposed generator, simulation results were obtained by solving the aforementioned equations and comparing the results with those obtained experimentally using the proposed prototype machine. The turn-off angle is sited at $45^{\circ}$ while the turn-on angle at $20^{\circ}$ (conduction period $25^{\circ}$ ). Figures (5) and (6) show the simulated and experimental results of steady state phase voltage, load voltage, phase current, and load current for the proposed generator.

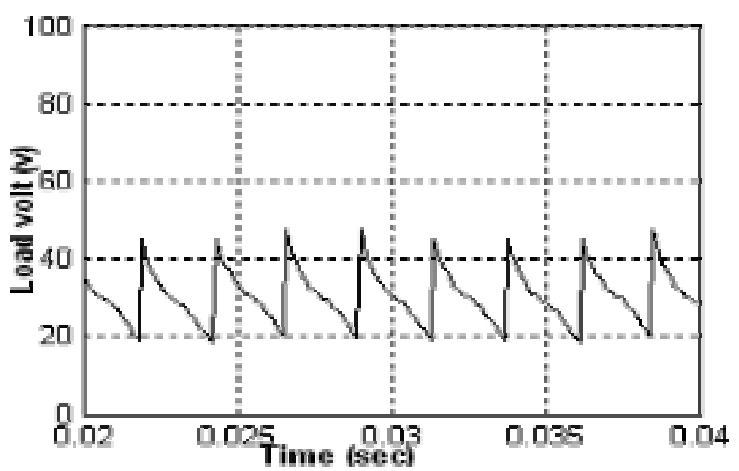

(b)

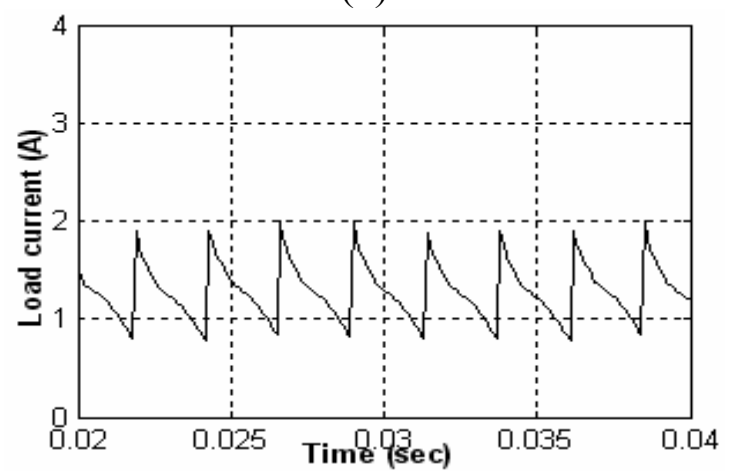

(d)

Fig. (5) The simulation results. 


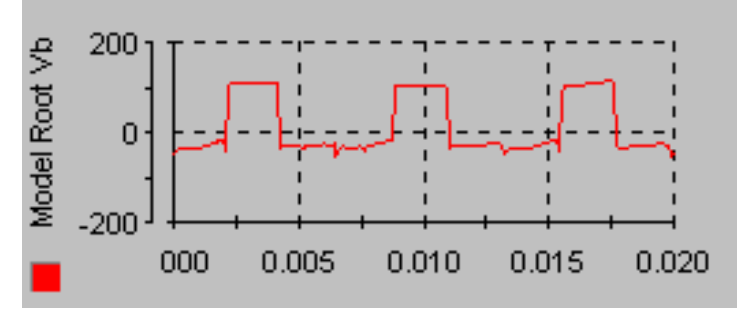

(a) Phase volt (V) vs. time (sec.)

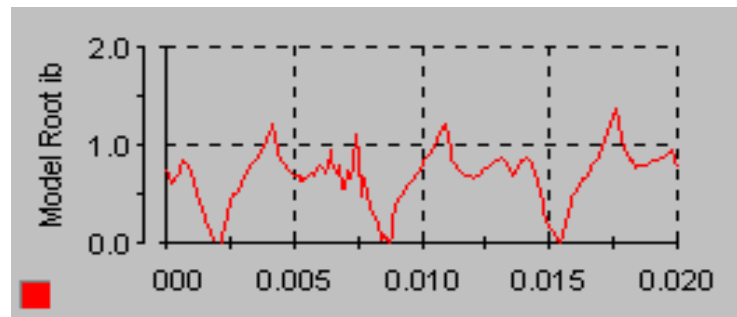

(c) Phase current (A) vs. time (sec.)

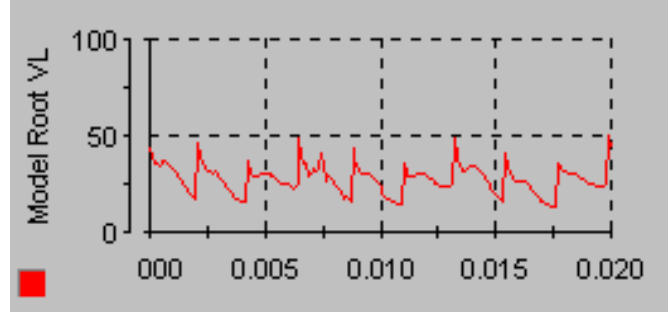

(b) Load volt (V) vs. time (sec.)

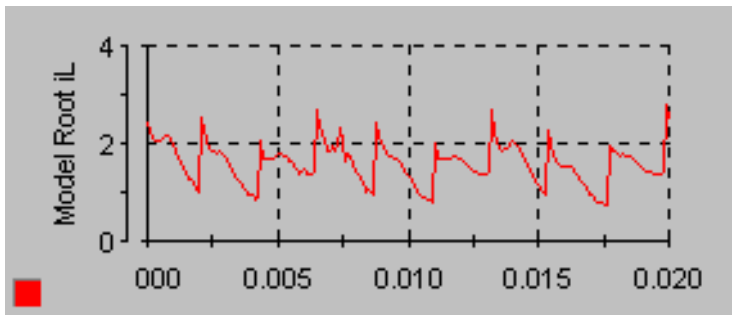

(d) Load current (A) vs. time (sec.)

Fig.(6) The experimental results.

During the excitation period the applied positive voltage makes the current build up, while, during generation period the current decays to be zero. During the generation mode, the load supplied from the energy stored in SRG phases. The results are obtained at $2100 \mathrm{rpm}, 110$ supply voltage and $\mathrm{RL}=18$ $\Omega$. A closed correlation between the experimental and simulated results can be clearly observed.

In order to satisfy the usage of SRG, the excitation penalty (E) must be studied. The excitation penalty is defined as the relative amount of excitation power $\mathrm{P}_{\text {exe }}$ to output power $\mathrm{P}_{\text {out }}$ and may be given by [9];

$$
\mathrm{E}=\frac{\mathrm{P}_{\text {exe }}}{\mathrm{P}_{\text {out }}}
$$

Fig (7) shows the simulated results of the variation of excitation penalty with the shaft speed. It can be observed that the excitation penalty is decreased by increasing the speed. Also, the excitation penalty is a relatively small fraction and then the exhibition of generation is validated.

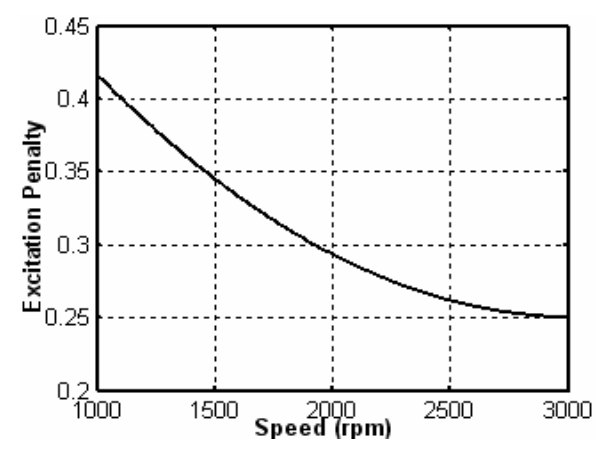

Fig. (7) Variation of excitation penalty with speed

\section{MAXIMUM POWER TRACKING WITH A VARIABLE SPEED WIND TURBINE}

Energy available in wind is basically the kinetic energy of large masses of air moving over the earth's surface. Blades of the wind turbine receive this kinetic energy, which is then transformed to mechanical or electrical forms depending on the available power converter apparatus.

The output power of wind turbine is a nonlinear function of the turbine shaft speed and also dependent on wind velocity. There are conditions for maximum output power at different values for both wind velocity and turbine shaft speed. Fig (8) shows this relation for a specified wind turbine, which can be calculated using cube function of the turbine shaft speed $(\omega)$,

$$
\mathrm{P}_{\max }=\mathrm{K} \omega^{3}
$$

Where $\mathrm{K}$ depends on the blade aerodynamics and wind turbine parameters.

As shown in Fig. (9), a closed loop power control is used to enforce the SRG output power to track the maximum power of wind turbine for different wind velocities. The average output power $\left(\mathrm{P}_{\text {out }}\right)$ of the SRG may be computed by product the average load voltage and load current. Also the SRG average input excitation power $\left(\mathrm{P}_{\text {exe }}\right)$ can be calculated by producing the average supply dc voltage and current. Then, the SRG input mechanical power can be calculated by:

$$
\mathrm{P}_{\mathrm{m}}=\mathrm{P}_{\text {out }}-\mathrm{P}_{\text {exe }}
$$




\section{A.F. Ahmed, F. El-Kholy, A.S. Abd El-Ghafaar, and A. Osheiba, "Performance Analysis and Control of a SRG"}

The input mechanical power must be equal the maximum output of turbine at specified wind velocity. So, $\mathrm{P}_{\text {ref }}$ is calculated by equation (8) and compared with $\mathrm{P}_{\mathrm{m}}$ from equation (9) and PI controller is used to determine the turn on angle of each phase.

The system described in Fig. (9) is analyzed using the simulation program and tested under a sudden wind velocity changes. Fig (10-a) shows the corresponding sudden changes in $\mathrm{P}_{\text {ref }}$ and the SRG input mechanical power response. The results obtained indicate that the SRG input power changes follow well the command maximum output power of the wind turbine. Fig (10-b) shows the response of the SRG output power. The step change in a wind shaft speed is shown in Fig $(10-c)$. The results indicate that the shaft speed varies from $2000 \mathrm{rpm}$, to $1800 \mathrm{rpm}$ at time $3 \mathrm{sec}$, then to $2200 \mathrm{rpm}$ at time 6 $\mathrm{sec}$ and then to $1900 \mathrm{rpm}$ at time $11 \mathrm{sec}$. The corresponding responses for turn on angle for each phase are shown in Fig. (10-d).

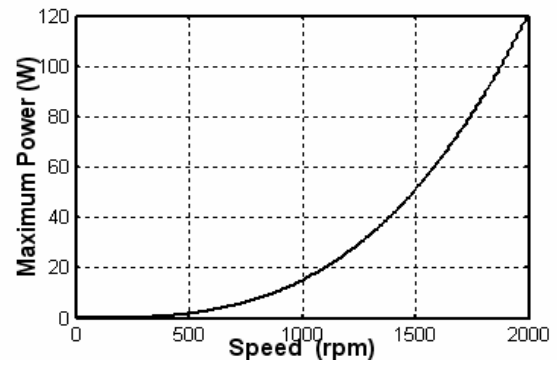

Fig. 8 A wind turbine maximum power curve

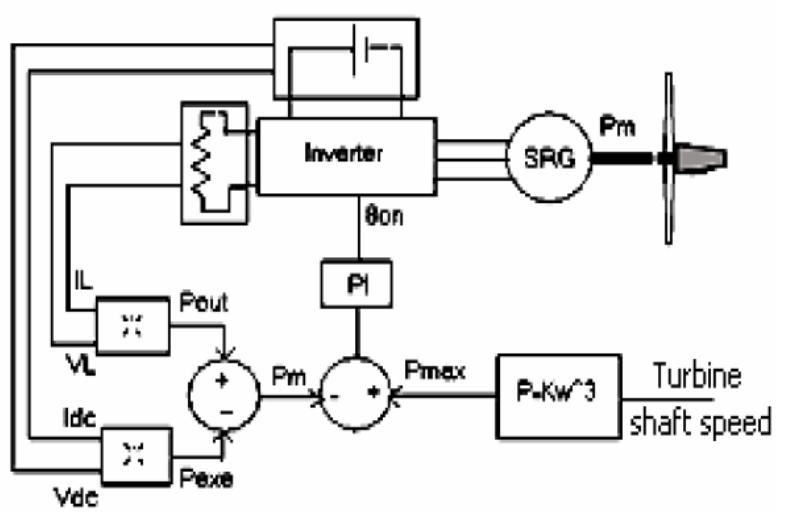

Fig (9) Block diagram of a closed loop control for SRG

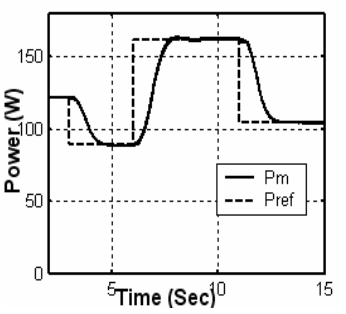

Fig (10-a)

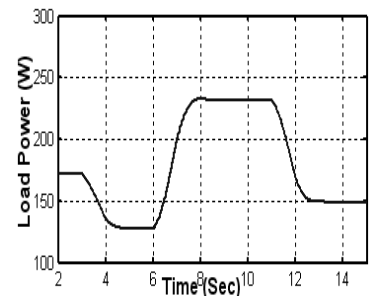

Fig (10-a)

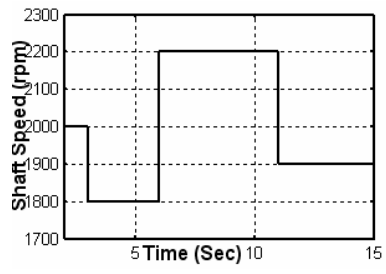

Fig (10-c)

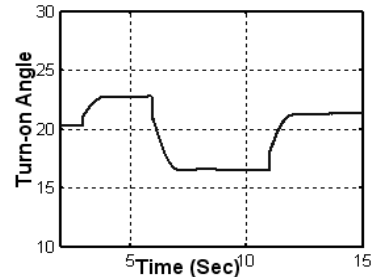

Fig (10-d)
Fig (10) Responses of a closed loop control for maximum power tracking of wind turbine.

\section{VOLTAGE STABILIZATION}

The voltage stabilization was used to obtain a constant output voltage at variable load resistance by controlling the turn on angle. The closed loop shown in Fig. (11), where the reference voltage is compared with the average feed back load voltage, the output of the PI controller is the turn on angle $\Theta_{\text {on }}$.

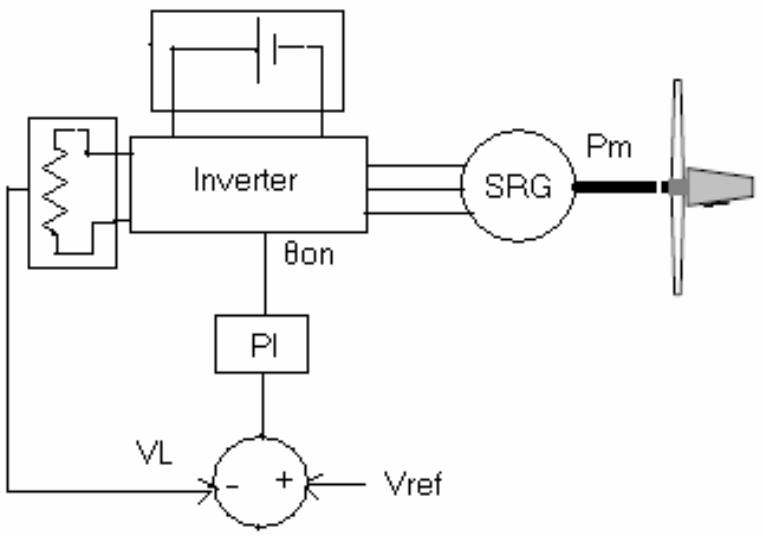

Fig (11) Closed loop control for a SRG voltage stabilizer

The simulation results for the SRG voltage stabilizer are shown in Fig. (12). Figure (12.a) shows a sudden change in the load resistance. The response of the output load voltage under a sudden load change is shown Fig. (12.b). The turn-on variation is shown in Fig (12.c). The results indicate that the output voltage of the SRG tracks the command voltage very well.

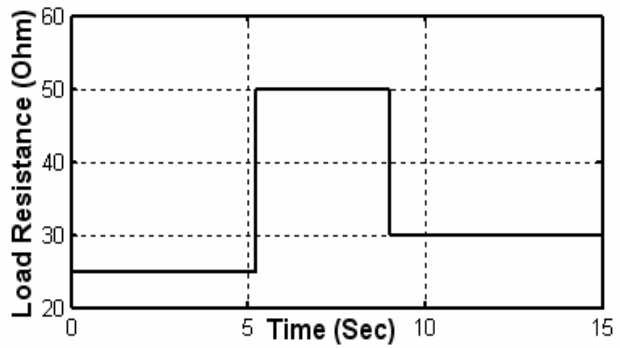

Fig (12-a) 


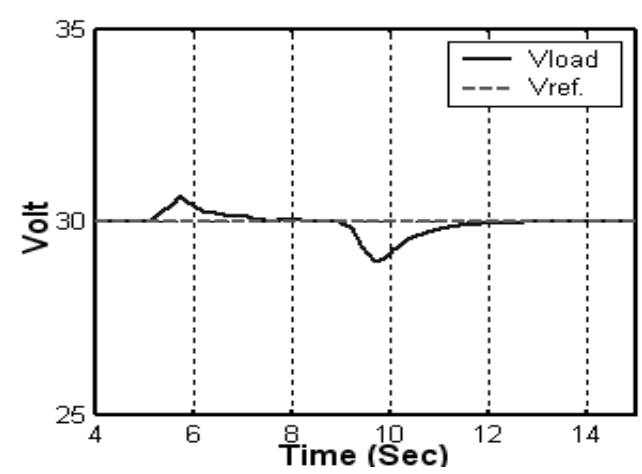

Fig (12-b)

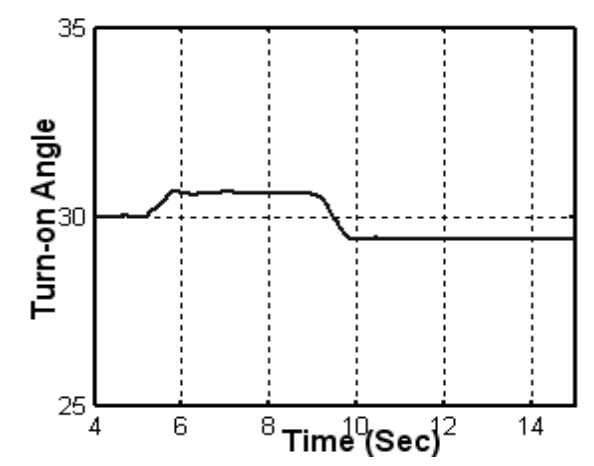

Fig (12-c)

Fig.(12) Simulated results for the SRG with voltage stabilizer.

\section{CONCLUSIONS}

This paper has presented a mathematical model by which the steady state and dynamic performances of a switched reluctance generator could be successfully predicted. In order to keep the load voltage constant under varying load conditions, a voltage stabilization was implemented and used. A closed loop control system was proposed, so that the output power of the SRG could track the maximum power of a wind turbine. The results indicated that the excitation penalty of the proposed generator might be improved by increasing the shaft speed. Test results are encouraging and the system promise to be a viable alternator to the conventional types. A close correlation between the experimental and simulated results was found which verifies the validity of the proposed analysis.

\section{REFERENCES}

[1] B. Fahimi, A. Emadi, and R. B. Sepe, Jr.," A Switched Reluctance Machine-Based Starter/Alternator for More Electric Cars", IEEE Trans. on Energy Conversion, Vol.19, No.1, March 2004.
[2] H. Chen, and Z. Shao, "Turn-on Angle Control For Switched Reluctance Wind Power Generator System", IEEE Industrial Electronics Society, November 2-6, 2004, Busan,Korea.

[3] I. J. Iglesias, L. G.Tabarés, M. Lafoz, J. Calero, S. Portillo, I. Cruz, F.Toral, P. Abramiam, "A Flywheel Switched Reluctance Motor Drive for Wind Energy Applications", Centro de Investigaciones Energéticas MedioAmbientales y Tecnológicas (CEDEX) Av Complutense ,22,228040, Madrid

[4] G. Gallegos-Lopez, F. Reiter,Jr ., K. Rajashekara, J. Krefta," 300kw Switched Reluctance Generator for Hybrid Vehicle Applications", SAE 2002 World Congress Detroit, Michigan March 4-7,2002.

[5] P. Zai-Ping, J. Ying, Z. Hui," Study on switched reluctance generator", Journal Zhejiang Univ SCI 2004 5(5), pp. 594-602.

[6] D. A. Torrey," Switched Reluctance Generators and Their Control", IEEE Trans. Industrial Electronics, VOL.49, NO.1, February 2002.

[7] M. A. Abdulatif "Design Considerations and Performance of Switched Reluctance Motors" Pd.D. Thesis, Faculty of Engineering, Menofia University, Shebin El-Kom, Egypt,2001.

[8] M. K. El-Nemr, M. A. Al-Khazendar, E. M. Rashad, and M. A. Hassanin " Modeling and Steady-State Analysis of Stand-Alone Switched reluctance Generators" IEEE Power Engineering Society General Meeting 13.17 july 2003, Toronto, Ontario Canada, pp. 1894-1899

[9] C. Mademlis, I. Kioskeridis "Optimizing Performance in Current-Controlled Switched Reluctance Generators" IEEE trans. on energy conversion, vol. 20 no. 3, September 2005

\section{Appendix-1}

\begin{tabular}{|l|l|}
\hline Number of stator poles & 6 \\
\hline Number of rotor poles & 4 \\
\hline Number of phases & 3 \\
\hline Stator inner diameter & $77 \mathrm{~mm}$ \\
\hline Core axial length & $56.5 \mathrm{~mm}$ \\
\hline Stator outer diameter & $125 \mathrm{~mm}$ \\
\hline Rotor pole height & $14 \mathrm{~mm}$ \\
\hline Air gap length & $0.5 \mathrm{~mm}$ \\
\hline Stator core width & $12.5 \mathrm{~mm}$ \\
\hline Shaft diameter & $13 \mathrm{~mm}$ \\
\hline Stator pole arc & $37^{\circ}$ \\
\hline Rotor pole arc & $45^{\circ}$ \\
\hline Number of turns $/$ phase & 420 \\
\hline
\end{tabular}

